\title{
Pengembangan Aplikasi Location Based Service Pariwisata berbasis Android Studi Kasus Kabupaten Toraja Utara
}

\author{
Ishak U. Saputra $^{1)}$, Alicia A. E. Sinsuw ${ }^{2)}$, Xaverius B. N. Najoan ${ }^{3)}$ \\ 1,2,3 Program Studi Teknik Informatika, Fakultas Teknik, Universitas Sam Ratulangi \\ E-mail : $120216085 @$ student.unsrat.ac.id ${ }^{1)}$, alicia.sinsuw@unsrat.ac.id ${ }^{2)}$,xnajoan@unsrat.ac.id ${ }^{3)}$
}

\begin{abstract}
Abstrak - Kabupaten Toraja Utara adalah sebuah kabupaten di Provinsi Sulawesi Selatan, Indonesia. Ibukotanya adalah Rantepao. Kabupaten ini dibentuk berdasarkan Undang-Undang Nomor 28 Tahun 2008 yang merupakan pemekaran dari Kabupaten Tana Toraja. Kabupaten Toraja Utara merupakan salah satu barometer perkembangan pariwisata nasional. Sektor pariwisata menjadi sektor andalan bukan hanya oleh pemerintah daerah, tetapi juga partisipasi lapisan masyarakatnya. Begitu pesatnya perkembangan Teknologi yang mencakup segala bidang, salah satunya dalam bidang Sistem Informasi seperti aplikasi Android yang dapat digunakan untuk menampilkan informasi wisata dan sarana penunjang wisata seperti hotel dan rumah makan. Berdasarkan tujuannya, penelitian ini berhasil menghasilkan aplikasi Location Based Service berbasis Android. Location Based Service merupakan layanan informasi yang dapat diakses menggunakan piranti mobile yang dapat digambarkan sebagai suatu layanan yang berada pada pertemuan tiga teknologi yaitu Global Positioning System (GPS), Internet Service, dan Mobile Devices. Android juga menyediakan akses dan integrasi dengan layanan Google Maps. Proses pembuatan aplikasi ini menggunakan metode Rapid Application Development (RAD) yang terdiri dari 3 fase yaitu Requirements Planning, RAD Design Workshop, dan Implementation. Untuk pengembangan lanjutan aplikasi Location Based Service Pariwisata berbasis Android di Kabupaten Toraja Utara dengan menambahkan fitur-fitur lain yang lebih menunjang.
\end{abstract}

Kata Kunci: Android, Global Positioning System, Google Maps, Internet Service, Location Based Service, Mobile Devices, Pariwisata, Rapid Application Development.

\section{PENDAhuluan}

Pengembangan pariwisata di suatu daerah tujuan wisata harus didasarkan pada perencanaan, pengembangan, dan arah pengelolaan yang jelas agar semua potensi yang dimiliki suatu daerah tujuan wisata dapat diberdayakan secara optimal untuk meningkatkan kesejahteraan masyarakat. Untuk mendapatkan hasil yang optimal, pengembangan pariwisata tidak hanya dikerjakan oleh satu pihak tetapi merupakan kerjasama dari berbagai pihak, baik kalangan pengusaha (swasta), tokoh masyarakat maupun pihak pemerintah daerah.

Kabupaten Toraja Utara adalah sebuah kabupaten di Provinsi Sulawesi Selatan, Indonesia. Ibukotanya adalah Rantepao. Kabupaten ini dibentuk berdasarkan UndangUndang Nomor 28 Tahun 2008 yang merupakan pemekaran dari Kabupaten Tana Toraja ${ }^{[1]}$. Kabupaten Toraja Utara merupakan salah satu barometer perkembangan pariwisata nasional. Daerah tersebut tidak hanya terkenal di dalam negeri tetapi juga di mancanegara. Sektor pariwisata menjadi sektor andalan bukan hanya oleh pemerintah daerah, tetapi juga partisipasi lapisan masyarakatnya.

Selain terkenal dengan bangunan rumah adatnya yang sangat unik, Toraja juga dikenal dengan upacara kematiannya yang disebut dengan Rambu Solo, makanan khas yang enak dan juga terdapat banyak objek-objek wisata yang dapat membuat para wisatawan kagum akan keindahan dan keunikannya. Banyaknya pilihan objek wisata yang terdapat di Kabupaten Toraja Utara ini dapat membuat bingung para wisatawan untuk memilih tempat tujuan wisata mulai dari yang terdekat dari tempat penginapan para wisatawan, berkaitan dengan itu penulis mencoba untuk mengembangakan sebuah aplikasi berbasis android pencarian objek wisata di Kabupaten Toraja Utara.

Location Based Service (LBS) merupakan sebuah service untuk memberikan informasi sesuai lokasi kita berada. Contohnya menunjukan titik terdekat dari kita, seperti ATM, SPBU, dan Rumah Sakit, Rumah Makan, Penginapan bahkan juga lokasi seseorang. Teknologi yang diaplikasikan di mobile phone saat ini yaitu Global Positioning System (GPS) yang dapat di kombinasikan. Location-Based Service (LBS) memanfaatkan teknologi GPS. Android juga memudahkan seorang developer dalam mengembangkan aplikasi seperti aplikasi LBS, karena Android menyediakan akses dan integrasi dengan layanan Google Maps. 


\section{E-Journal Teknik Informatika Vol 12, No.1 (2017) ISSN : 2301 - 8364}

\section{LANDASAN TEORI}

A. Pariwisata

Pariwisata merupakan salah satu kebutuhan manusia. Dengan melakukan wisata, manusia dapat sejenak melepas penat, lelah dan menghilangkan stress, serta sejenak melupakan masalah yang dialami baik di rumah maupun di kantor. Berdasarkan Undang-Undang No. 9 Tahun 2009 pariwisata adalah berbagai macam kegiatan wisata dan didukung berbagai fasilitas serta layanan yang disediakan oleh masyarakat, pengusaha, pemerintah, dan pemerintah daerah $^{[2]}$.

\section{B. Smartphone}

Smartphone adalah telepon selular dengan mikroprosesor, memori, layar dan modem bawaan ${ }^{[3]}$. Smartphone merupakan ponsel multimedia yang menggabungkan fungsionalitas PC dan handset sehingga menghasilkan gadget yang mewah, di mana terdapat pesan teks, kamera, pemutar musik, video, game, akses email, tv digital, search engine, pengelola informasi pribadi, fitur GPS, jasa telepon internet dan bahkan terdapat telepon yang juga berfungsi sebagai kartu kredit.

\section{Android}

Android adalah sistem operasi yang digunakan di smartphone dan juga tablet PC. Fungsinya sama seperti sistem operasi Symbian di Nokia, iOS di Apple dan BlackBerry OS. Android tidak terikat ke satu merek Handphone saja, beberapa vendor terkenal yang sudah memakai Android antara lain Samsung, Sony Ericsson, HTC, Nexus, Motorolla, dan lain-lain. Android pertama kali dikembangkan oleh perusahaan bernama Android Inc., dan pada tahun 2005 di akuisisi oleh raksasa Internet Google.

Android dibuat dengan basis kernel Linux yang telah dimodifikasi, dan untuk setiap release-nya diberi kode nama berdasarkan nama hidangan makanan. Android dijual lebih murah dibandingkan dengan Blackberry atau iPhone meski fitur (hardware) yang ditawarkan Android lebih baik. Beberapa fitur utama dari Android antara lain WiFi Hotspot, Multi-touch, Multitasking, GPS, accelerometers, support java, mendukung banyak jaringan (GSM/EDGE, IDEN, CDMA, EV-DO, UMTS, Bluetooth, Wi-Fi, LTE \& WiMAX) serta juga kemampuan dasar handphone pada umumnya ${ }^{[4]}$.

\section{Location Based Service}

Location Based Service merupakan layanan informasi yang dapat diakses menggunakan piranti mobile melalui jaringan internet dan seluler serta memanfaatkan kemampuan penunjuk lokasi pada piranti mobile. LBS dapat digambarkan sebagai suatu layanan yang berada pada pertemuan tiga teknologi yaitu Geographic Information System, Internet Service, dan Mobile Devices. Layanan Berbasis Lokasi terdiri 5 komponen utama yaitu:
1. Mobile Devices

Suatu alat yang digunakan oleh pengguna untuk meminta informasi yang dibutuhkan.

2. Communication Network

Jaringan komunikasi yang mengirim data pengguna dan informasi yang diminta dari mobile terminal ke Service Provider kemudian mengirimkan kembali informasi yang diminta ke pengguna. Communication Network dapat berupa jaringan seluler (GSM, CDMA), Wireless Local Area Network (WLAN), atau Wireless Wide Area Network (WWAN)

3. Positioning Component

Untuk memproses sesuatu dalam mengendalikan layanan maka posisi pengguna harus diketahui peta.

4. Service and Application Provider

Penyedia layanan menawarkan berbagai macam layanan kepada pengguna dan bertanggung jawab untuk memproses informasi yang diminta oleh pengguna.

\section{Data and Content Provider}

Penyedia layanan tidak selalu menyimpan semua data yang dibutuhkan yang bisa diakses oleh pengguna. Untuk itu, data dapat diminta dari content provider $^{[5]}$. Komponen dasar LBS digambarkan pada gambar dibawah ini:

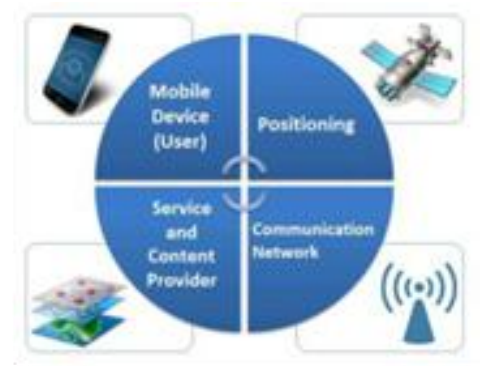

Gambar 1. Komponen dasar LBS

\section{E. Global Positioning System}

Global Positioning System atau GPS adalah sistem untuk menentukan letak di permukaan bumi dengan bantuan penyelarasan sinyal satelit. Bagian yang paling penting dalam sistem navigasi GPS adalah beberapa satelit yang berada di orbit bumi atau yang sering kita sebut di ruang angkasa. Satelit GPS saat ini berjumlah 24 unit yang semuanya dapat memancarkan sinyal ke bumi yang lalu dapat ditangkap oleh alat penerima sinyal tersebut atau GPS Tracker ${ }^{[6]}$. 


\section{E-Journal Teknik Informatika Vol 12, No.1 (2017) ISSN : 2301 - 8364}

\section{METODOLOGI PENELITIAN}

\section{A. Lokasi Penelitian}

Lokasi dari studi kasus dalam penelitian ini adalah berbagai tempat-tempat wisata dan sarana penunjang pariwisata Kabupaten Toraja Utara.

\section{B. Data Penelitian}

Pada penelitian ini data yang dikumpulkan untuk menunjang pengerjaan penelitian:

1. Data Primer

Data primer yang diperoleh dari observasi langsung di lokasi penelitian yakni Kabupaten Toraja Utara.

2. Data Sekunder

Data sekunder yang didapatkan melalui media perantara secara tidak langsung bersumber dari jurnal, e-book, dan informasi lainnya yang berhubungan dengan pembuatan aplikasi.

\section{Tahapan Pengembangan}

Model rekayasa perangkat lunak yang digunakan adalah model RAD (Rapid Application Development). RAD adalah salah satu metode pengembangan suatu sistem informasi dengan waktu yang relatif singkat ${ }^{[7]}$. RAD memiliki 3 tahapan utama yaitu :

1. Requirement Planing

Fase ini merupakan proses melakukan pengumpulan informasi yang sesuai dengan penelitian yang akan dikembangkan. Semua informasi yang dibutuhkan dikumpul untuk menjadi data yang digunakan dalam proses pembuatan.

\section{Design Workshop}

Fase ini merupakan fase untuk merancang dan memperbaiki aplikasi atau sistem yang telah digambarkan. Fase ini digambarkan dengan deskripsi Pemodelan Bisnis, Pemodelan Data, Pemodelan Proses, Pembuatan Aplikasi, dan Pengujian.

\section{a. Pemodelan Bisnis}

Tahap ini dimana aliran informasi pada fungsifungsi bisnis dimodelkan untuk mengetahui informasi apa yang mengendalikan proses bisnis, informasi apa yang dihasilkan, siapa yang membuat informasi itu, kemana saja informasi mengalir, dan siapa yang mengolahnya. Untuk mempermudah gambaran dari hubungan sistem dan pengguna maka digunakan use case diagram.
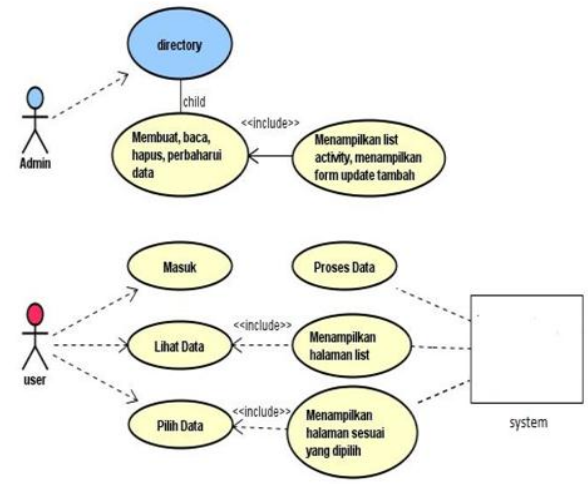

Gambar 2. Use Case Diagram

b. Pemodelan Data

Database atau basis data yang digunakan adalah Real Time Database yang di sediakan oleh Firebase yang merupakan sebuah NoSQL database. NoSQL database menyimpan data menggunakan format JSON (Java Script Object Natation).

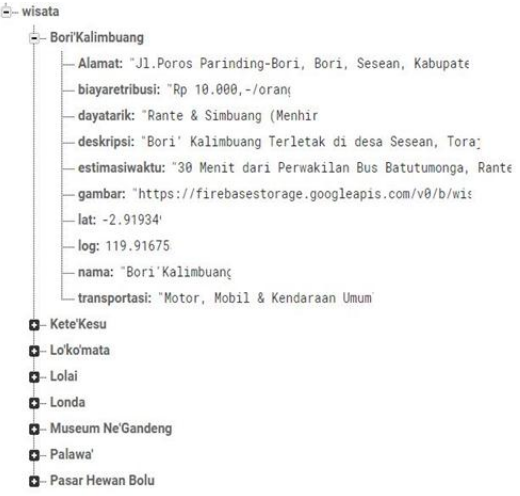

Gambar 3. Struktur Data Wisata pada Firebase

Pada struktur di atas terdapat sepuluh key yaitu lat yang berisi latitude, key log yang berisi longitude dari posisi user, key Alamat yang berisi alamat dari wisata, key biayaretribusi berisi pungutan untuk masuk lokasi, key dayatarik berisi dayatarik dari wisata, key deskripsi berisi sedikit informasi dari lokasi wisata, key estimasiwaktu berisi perkiraan waktu menuju lokasi, key gambar berisi gambar wisata, key nama berisi nama dari wisata, dan key transportasi berisi transportasi yang bisa digunakan menuju lokasi. 


\section{E-Journal Teknik Informatika Vol 12, No.1 (2017) ISSN : 2301 - 8364}

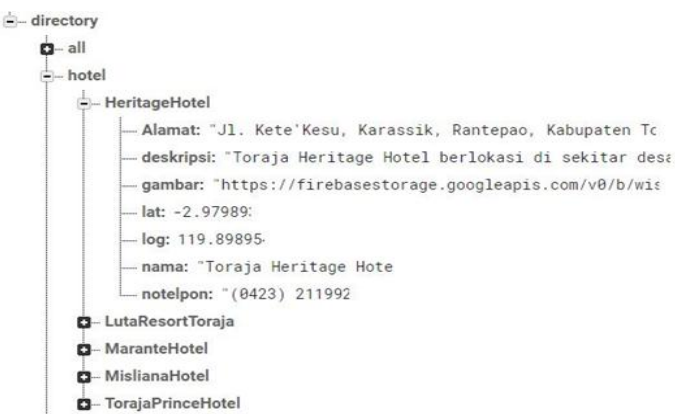

Gambar 4. Struktur Data Hotel pada Firebase

Pada struktur di atas terdapat tujuh key yaitu lat yang berisi latitude, key log yang berisi longitude dari posisi user, key Alamat yang berisi alamat dari hotel, key deskripsi berisi sedikit informasi dari hotel, key gambar yang berisi gambar hotel, key nama yang berisi nama dari hotel, dan key notelpon berisi nomor telepon dari hotel.

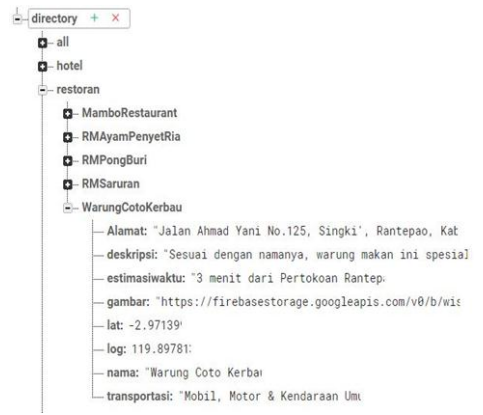

Gambar 5. Struktur Data Restoran pada Firebase

Pada struktur di atas terdapat delapan key yaitu lat yang berisi latitude, key log yang berisi longitude dari posisi user, key Alamat yang berisi alamat dari rumah makan, key deskripsi berisi sedikit infromasi dari rumah makan, key estimasiwaktu berisi perkiraan waktu menuju lokasi, key gambar berisi gambar rumah makan, key nama berisi nama dari rumah makan dan key transportasi berisi transportasi yang bisa digunakan menuju lokasi.

\section{c. Pemodelan Proses}

Pada tahap ini perancangan sistem dimodelkan berdasarkan gambaran dan prilaku dari objek dengan menggunakan Sequence Diagram dan Activity Diagram.

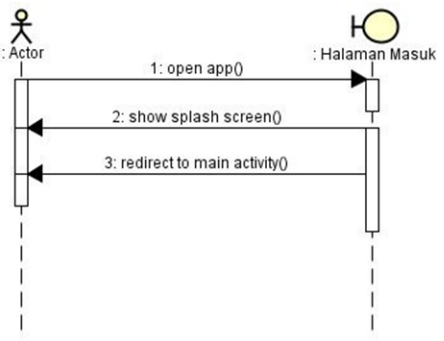

Gambar 6. Sequence Diagram Masuk Aplikasi

Sequence Diagram diatas menunjukkan interaksi antara sistem dan pengguna baik sebagai admin maupun sebagai pengguna biasa.

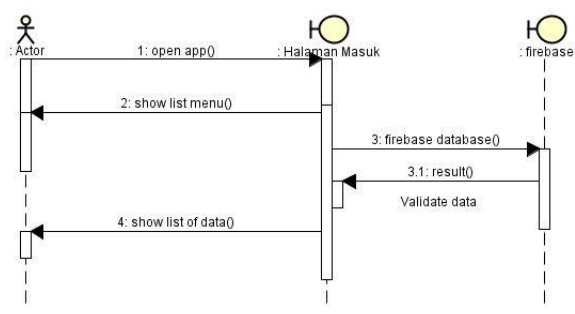

Gambar 7. Sequence Diagram Halaman Utama Aplikasi

Sequence Diagram diatas menunjukkan interaksi user dan sistem dalam hal mengkases informasi berupa list atau daftar dari kontent.

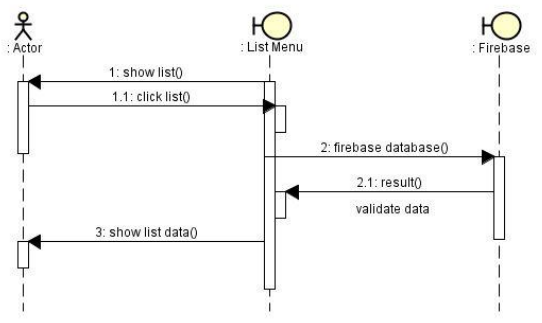

Gambar 8. Sequence Diagram Melihat Data/Kontent

Pada gambar diatas sistem akan menampilkan semua data atau kontent yang terdapat dalam kategori yang user inginkan.

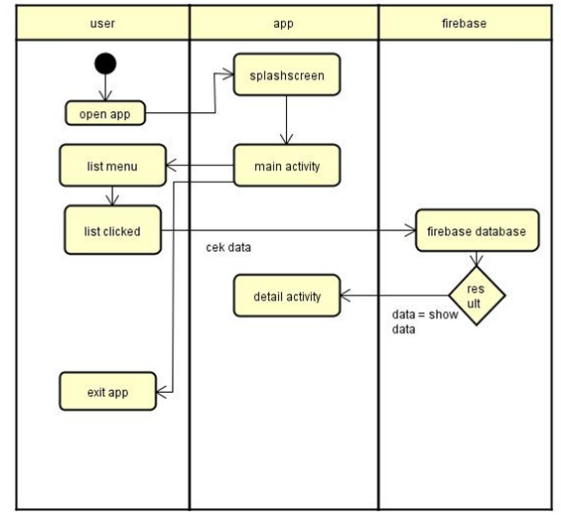

Gambar 9. Activity Diagram Aplikasi

Activity Diagram aplikasi diatas menunjukkan urutan aktifitas dari penggunaan aplikasi.

\section{d. Pembuatan Aplikasi}

Pada tahap ini dilakukan beberapa persiapan untuk membangun aplikasi dalam bentuk gambaran. Aplikasi yang dibangun berupa aplikasi mobile. 

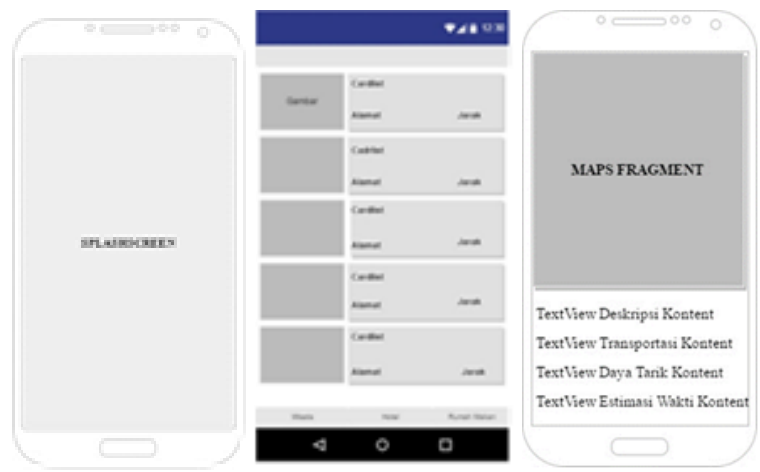

Gambar 10. Desain Antarmuka

\section{e. Pengujian}

Pada tahap ini dilakukan pengujian aplikasi menggunakan metode Black Box. Pengujian kotak hitam, juga disebut sebagai pengujian perilaku, berfokus pada persyaratan fungsional perangkat lunak.

\section{Implementation}

Fase ini, semua desain dari sistem yang sudah dibuat dan disetujui dikembangan menjadi sebuah program.

\section{HASIL DAN PEMBAHASAN}

Setelah melakukan semua tahapan dari metode Rapid Application Development yang di kemukanan pada tahap sebelumnya, dilanjutkan dengan hasil dari perancangan yang di lakukan berdasarkan tujuan awal dari pengembangan ini yaitu mengembangakan aplikasi Location Based Sevice Pariwisata berbasis Mobile dengan sistem operasi Android.

\section{A. Antarmuka Aplikasi}

1. Tampilan SplashScreen

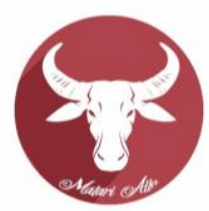

\section{Gambar 11. Tampilan SplashScreen}

Splashscreen ini merupakan tampilan halaman awal yang terdapat sebuah gambar yang akan dieksekusi setelah pengguna membuka aplikasi.
2. Tampilan Main Activity
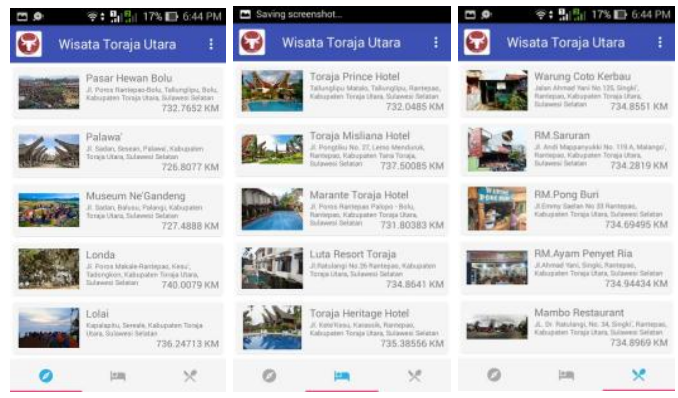

Gambar 12. Tampilan Main Acitivity

Tampilan ini akan muncul setelah halaman splashscreen selesai dieksekusi. Pada main activity ini tedapat list content, menu tablayout dan menu toolbar. Menu tablayout berisi button wisata, button hotel dan button restoran. List content berisi gambar, nama objek, alamat objek dan jarak pengguna menuju objek. Menu toolbar berisi button Galery dan button Maps, dimana button Galery berisikan kumpulan gambar-gambar objek wisata sedangkan button Maps berisikan peta dan markermarker wisata, hotel dan restoran serta lokasi kita berada saat ini.

3. Tampilan Menu Galery \& Maps pada Action Bar

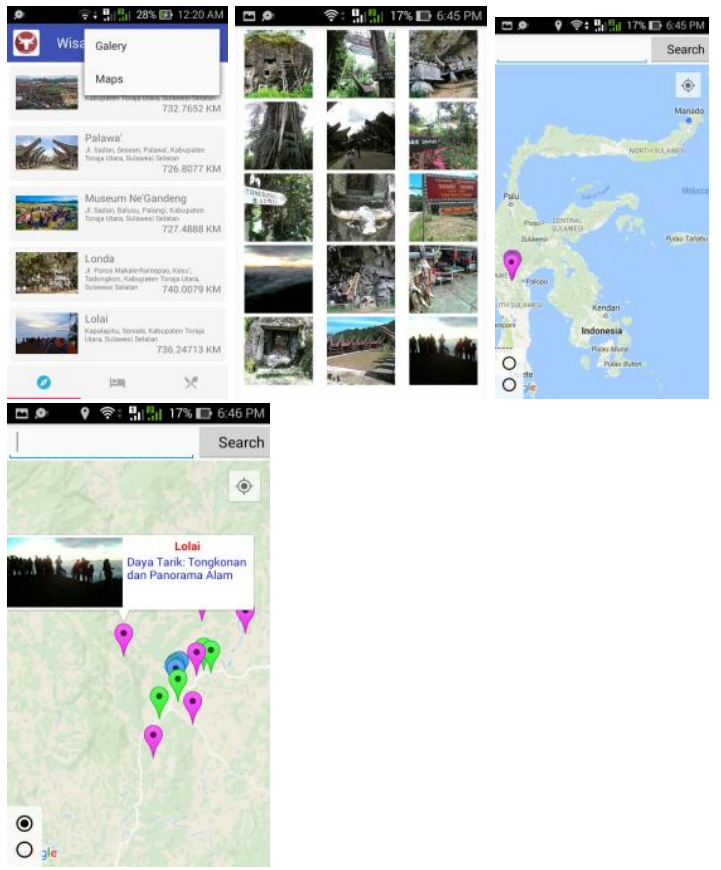

Gambar 13. Tampilan Menu Galery \& Maps

Menu toolbar ini berada diatas pojok kanan atas. Menu toolbar berisi button Galery dan button Maps, dimana button Galery berisikan kumpulan gambar-gambar objek wisata sedangkan button Maps berisikan peta dan marker-marker wisata, hotel dan restoran serta lokasi kita berada saat ini. 
4. Tampilan Detail Activity

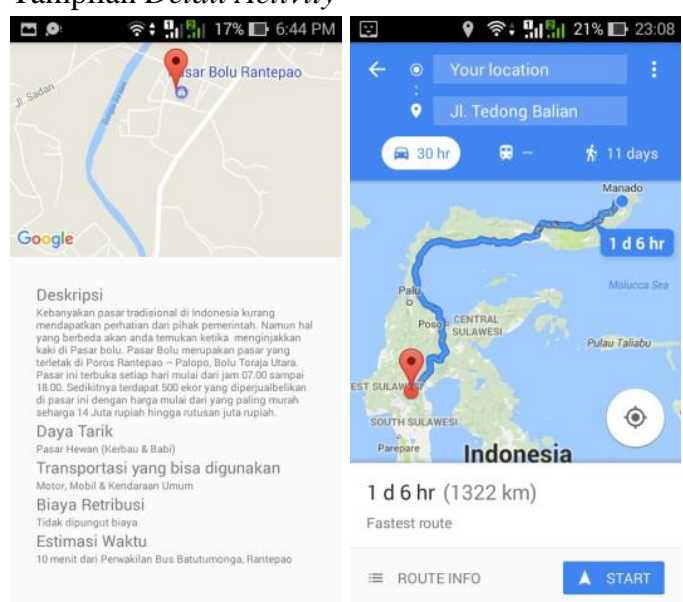

Gambar 14. Tampilan Detail Activity

Pada detail activity ini disajikan data detail berupa tampilan maps dengan marker posisi user berada dan marker posisi tujuan serta informasi konten sesuai request dari user.

\section{B. Pengujian}

Pengujian dilakukan terhadap beberapa fitur yang sudah di tetapkan dan bertujuan untuk dapat mengetahui apakah aplikasi yang telah dibuat dapat berjalan dengan baik. Black box testing berfokus pada spesifikasi fungsional dari perangkat lunak. Aplikasi dikatakan dapat berfungsi dengan baik yaitu pada saat input diberikan dan output memberikan hasil sesuai dengan spesifikasi sistem yang dibuat.

Tabel 1. Rekap pengujian

\begin{tabular}{|c|c|c|c|}
\hline $\begin{array}{c}\text { Item } \\
\text { Pengujian }\end{array}$ & Skenario Pengujian & $\begin{array}{c}\text { Hasil } \\
\text { Pengujian }\end{array}$ & Keterangan \\
\hline Splashscreen & $\begin{array}{l}\text { User melihat tampilan gambar } \\
\text { sekilas sebelum menuju menu } \\
\text { utama }\end{array}$ & $\begin{array}{c}\text { Dapat } \\
\text { dilihat pada } \\
\text { Gambar 11 }\end{array}$ & Berhasil \\
\hline Menu Utama & $\begin{array}{l}\text { User dapat melihat dan } \\
\text { memilih list menu yang ada } \\
\text { dalam aplikasi }\end{array}$ & $\begin{array}{c}\text { Dapat } \\
\text { dilihat pada } \\
\text { Gambar 12 }\end{array}$ & Berhasil \\
\hline Detail List & $\begin{array}{l}\text { User mendapatkan dan } \\
\text { melihat informasi dari list } \\
\text { yenu telah dipilih serta posisi } \\
\text { user menuju lokasi yang } \\
\text { disinkronkan dengan Google }\end{array}$ & $\begin{array}{c}\text { Dapat } \\
\text { dilihat pada } \\
\text { Gambar 14 }\end{array}$ & Berhasil \\
\hline Fitur Menu \\
Maps
\end{tabular}

\section{PENUTUP}

\section{A. Kesimpulan}

Berdasarkan hasil penelitian yang telah dikembangkan dalam Pengembangan Aplikasi Location Based Service Pariwisata berbasis Android di Kabupaten Toraja Utara, telah dihasilkan suatu aplikasi yang dapat mengenalkan dan memberikan informasi jarak dan posisi beserta informasi mengenai Pariwisata yang ada di Kabupaten Toraja Utara.

Dengan menggunakan teknologi Location Based Service dapat membantu menemukan lokasi yang akan dikunjungi oleh pengguna dengan tepat.

\section{B. Saran}

Saran untuk pengembangan lanjutan Aplikasi Location Based Service Pariwisata berbasis Android di Kabupaten Toraja Utara dengan menambahkan fitur-fitur lain yang lebih menunjang.

\section{DAFTAR PUSTAKA}

[1] Sejarah Kabupaten Toraja Utara, [online]. Tersedia: http://www.torajaparadise.com/2013/04/profil-

kabupaten-toraja-utara.html. [Diakses pada tanggal 6 April 2017]

[2] Definisi Pariwisata, [online]. Tersedia: http://karyatulisilmiah.com/pengertian-pariwisata/.

[Diakses pada tanggal 9 April 2017]

[3] Williams, B.K. and Sawyer, S.C. 2011. "Using Information Technology: A Practical Introduction to Computers \& Communications. (9th edition)". New York: McGraw-Hill.

[4] Arti Android beserta fasilitas yang ada didalamnya, [online].Tersedia:http://www.infoteknologi.com/selul ar/apa-itu-android/. [Diakses pada 8 April 2017]

[5] Akbar Nuzul Putra, Toufan D., Tambunan, Kurniawan Nur Ramadhan."Aplikasi Layanan Kesehatan Kota Bandung Menggunakan Metode Location-Based Services (LBS) pada Android". Penelitian, Politeknik Telkom, Bandung. (2011)

[6] Pengertian GPS dan Fungsi GPS, [online]. Tersedia:htpp://bidakara.ac.id/pengertian-gps-carakerja-gps-dan-fungsi-gps. [Diakses pada 9 April 2017]

[7] Noertjahyana Agustinus. 2002. Studi Analisis Rapid Aplication Development Sebagai Salah Satu Alternatif Metode Pengembangan Perangkat Lunak. Jurnal Informatika, Vol. 3 no. 2. 


\section{E-Journal Teknik Informatika Vol 12, No.1 (2017) ISSN : 2301 - 8364}

\section{TENTANG PENULIS}

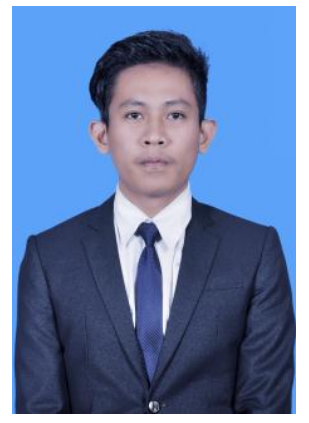

Ishak Untung Saputra, lahir di Makassar pada tanggal 7 Maret 1995. Penulis menempuh Pendidikan secara berturut-turut di SD Frater Bhakti Luhur Makassar (2000-2006), SMP Negeri 8 Makassar (20062009), dan lulus dari SMA Advent Timika Jurusan IPA (2009-2012).

Pada tahun 2012, penulis melanjutkan studi di Program Studi Informatika, Jurusan Teknik Elektro, Fakultas Teknik, Universitas Sam Ratulangi. Selama masa kuliah, penulis telah menjalani kerja praktek di GMIM Pniel Bahu, Manado, serta mengikuti kegiatan Kuliah Kerja Nyata Terpadu di Desa Purworejo, Kecamatan Modayag, Kabupaten Bolaang Mongondow Timur. Selama kuliah penulis tergabung dalam organisasi kemahasiswaan yaitu, Himpunan Mahasiswa Elektro FT-Unsrat, Unsrat IT Community dan Mapala Pah'yaga'an Fakultas Teknik Universitas Sam Ratulangi. Penulis menyelesaikan studi di Program Studi Informatika, Jurusan Teknik Elektro, Fakultas Teknik, Universitas Sam Ratulangi pada 6 Oktober 2017. 